\title{
Distribuição das algas Calcárias incrustantes (Corallinales, Rhodophyta) em diferentes habitats na Praia do Forno, Armação dos Búzios, Rio de Janeiro
}

Frederico Tapajós de Souza Tâmega ${ }^{1,2^{*}}$ \& Marcia Abreu de Oliveira Figueiredo ${ }^{1}$

\begin{abstract}
RESUMO
(Distribuição das algas calcárias incrustantes (Corallinales, Rhodophyta) em diferentes habitats na Praia do Forno, Armação dos Búzios, Rio de Janeiro) As algas calcárias incrustantes ocupam grande variedade de habitats nos substratos duros. Neste estudo as características morfológicas destas algas foram relacionadas à influência de fatores ambientais. Coletas foram realizadas na Praia do Forno (RJ) utilizando transectos de linha com $10 \mathrm{~m}$ de comprimento com 30 pontos aleatórios para quantificação das algas calcárias. Aspectos morfológicos externos foram observados no estereomicroscópio e seções histológicas preparadas para identificação dos grupos/táxons. Seis grupos morfo-funcionais foram identificados sendo quatro mais abundantes: Hydrolithon samoënse (Foslie) D. Keats \& Y. Chamberlain dominou na região do mesolitoral (53\%) e no sublitoral (57-87\%) junto à clorofícea Codium spongiosum Harvey e em locais desprovidos de outras algas, expostos à ação das ondas e alta densidade de ouriços herbívoros. Spongites sp. foi abundante próximo às fendas nas rochas do mesolitoral (39-40\%). Lithophyllum sp. dominou desde o mesolitoral (44\%) até o sublitoral junto à Codium (43-74\%) e Sargassum (74-93\%). Houve discreta variação temporal na distribuição de H. samoënse e Lithophyllum sp. Talos protuberantes em Lithophyllum dominaram em locais de maior sedimentação enquanto talos planos de $H$. samoënse e Spongites sp. dominaram em locais de maior herbivoria. A distribuição dos grupos morfo-funcionais nos diferentes habitats concorda com padrões associados aos distúrbios bióticos e abióticos, previstos para comunidades de costões rochosos.
\end{abstract}

Palavras-chave: algas calcárias incrustantes, costões rochosos, distribuição, grupos morfo-funcionais, habitats.

\section{Abstract}

(Distribution of the crustose coralline algae (Corallinales, Rhodophyta) in different habitats at Praia do Forno, Armação dos Buzios, Rio de Janeiro) The crustose coralline algae occupy several different habitats in the rocky shores. In this study morphological characteristics of these algae were related to the influence of environmental factors. The algae collection was done at Praia do Forno (RJ) using $10 \mathrm{~m}$ transects lines with 30 random points to quantify coralline algae. The morphological aspects were observed by a stereomicroscope and anatomic sections were prepared to identify the groups/taxons. Six morphological groups were identified being four more abundant. Hydrolithon samoënse (Foslie) D. Keats \& Y. Chamberlain dominated on the littoral (53\%) and sublittoral zones together with the chlorophyte Codium spongiosum Harvey and on barren rocks, exposed to wave action and high density of herbivorous sea-urchins (57-87\%). Spongites sp was abundant on nearby rocky crevices on the littoral zone (39-40\%). Lithophyllum sp. dominated from littoral (44\%) to sublitoral zones together with Codium (43-74\%) and Sargassum (74-93\%). There was inconspicuous seasonal variation on the distribution of $H$. samoënse and Lithophyllum sp. Protuberant thalli of Lithophyllum dominated in places under high sedimentation while flat thalli of $H$. samoënse and Spongites dominated in areas with high herbivory. The distribution of form-functional groups in different habitats agrees with patterns associated with biotic and abiotic disturbances, expected for rocky shore communities.

Keywords: crustose coralline algae, rocky shore, distribution, form-functional groups, habitats.

\footnotetext{
Artigo recebido em 03/2005. Aceito para publicação em 08/2005.

${ }^{1}$ Instituto de Pesquisas Jardim Botânico do Rio de Janeiro, Programa Zona Costeira, Rua Pacheco Leão 915, 22460-230, Rio de Janeiro, RJ, Brasil tel./fax: (xx21) 3204-2149. Apoio: CNPq e FAPERJ.

${ }^{2}$ Programa de Pós-Graduação em Botânica, Museu Nacional - UFRJ, Quinta da Boa Vista s/nº 20940-040, Rio de Janeiro, RJ, Brasil.

*Autor para correspondência: ftapajos@jbrj.gov.br
} 


\section{INTRODUÇão}

As algas calcárias incrustantes (ou algas coralíneas) ocupam uma grande variedade de habitats nos substratos duros: poças de marés, rochas emergentes no mesolitoral e sublitoral (Littler 1972, Steneck 1986). A distribuição das algas coralíneas tem sido descrita principalmente para ambientes temperados (Adey 1966, 1971, Adey \& Adey 1973, Steneck \& Paine 1986, Steneck 1990). Estudos demonstram existir uma sazonalidade no crescimento de algas calcárias incrustantes em costões rochosos em regiões temperadas (Leukart 1994). A sucessão de espécies de algas calcárias incrustantes ao longo do tempo foi demonstrada para recifes coralíneos nos trópicos (Adey \& Vassar 1975, Nain 1993). No entanto, existe uma enorme carência de estudos sobre a distribuição e sucessão destas algas em costões rochosos na região tropical.

Características morfológicas nestas algas podem indicar adaptações a vários fatores ambientais, como exposição às ondas, luminosidade, competição, herbivoria (Steneck 1986, 1990). Seguindo os modelos sobre forma/ função propostos para outras algas (Littler \& Littler 1980, 1984), espécies de algas coralíneas foram separadas em grupos funcionais que refletem condições ambientais dos habitats (Steneck \& Dethier 1994). Entretanto, a plasticidade das características vegetativas nem sempre possibilita a determinação do táxon, devendo-se analisar características anatômicas e reprodutivas (Adey \& Adey 1973).

Devido às dificuldades taxonômicas, estudos ecológicos têm ignorado este grupo de algas. Por exemplo: características da superfície do talo (protuberâncias e cristas) podem variar de acordo com as condições ambientais, permitindo que gêneros e espécies distintos tornem-se semelhantes no aspecto externo (Irvine \& Chamberlain 1994). Sendo assim, este trabalho teve o objetivo de identificar as algas calcárias incrustantes e descrever sua distribuição nos diferentes habitats na Praia do Forno, município de Armação dos Búzios, no litoral fluminense.

\section{Material e Métodos}

\section{Descrição da área de estudo}

O local de estudo foi a Praia do Forno (Fig. 1), situada no Saco do Forno, município de Armação de Búzios, estado do Rio de Janeiro. A Praia do Forno é uma enseada estreita com profundidade máxima de $12 \mathrm{~m}$, protegida das ondulações do quadrante norte-leste, dominantes na maior parte do ano (Yoneshigue 1985). A praia é bastante conservada devido a pouca ação antrópica. Na época de maior pluviosidade, outubro a janeiro (Yoneshigue 1985), as águas são geralmente turvas e a visibilidade em torno de 1 metro. A temperatura da água varia de 18 a $24^{\circ} \mathrm{C}$ (medidas pontuais), podendo no período de setembro a março sofrer influência de ressurgência local, próximo ao Cabo de São Tomé (Valentim et al. 1978).

O local de estudo apresenta uma grande variabilidade de algas calcárias incrustantes. No lado direito da Praia do Forno, existem matacões próximo ao costão rochoso os quais estão expostos diretamente à ação das ondas. Estes são densamente cobertos por algas calcárias incrustantes e por herbívoros, potencialmente consumidores destas algas (principalmente os ouriços - Echinoidea). No lado esquerdo da Praia do Forno, o costão rochoso tem um declive suave e apresenta diferentes habitats, como fendas e regiões moderadamente expostas à ação das ondas. Neste lado, as macroalgas Codium spongiosum Harvey e

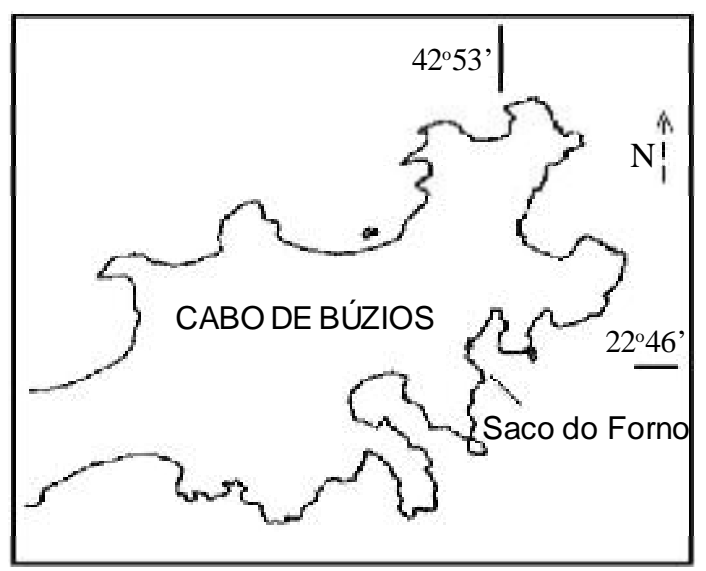

Figura 1 - Localização da área de estudo no Município de Armação dos Búzios, Rio de Janeiro. 
Sargassum furcatum Kützing são dominantes e recobrem em grande parte as algas calcárias incrustantes no sublitoral. No mesolitoral as algas formadoras de turfos são comumente encontradas na faixa inferior seguidas por algas calcárias incrustantes e uma população densa de herbívoros. Ainda neste lado da praia, os herbívoros mais comuns são os ouriços (Echinoidea), quitons (Polyplacophora), lapas e aplísias (Gastropoda - Archaeogastropoda e Aplysiacea), caranguejo (Crustacea - Decapoda) epeixes pequenos. Dentre estes, os consumidores potenciais das algas calcárias incrustantes são os ouriços, quitons e as lapas (Steneck 1986).

\section{Distribuição das algas calcárias}

As coletas foram realizadas em habitats no mesolitoral e sublitoral nos costões rochosos dos dois lados da Praia do Forno em 16.VII.98, 14.VIII.98, 27.V.99 e 3.XI.99. Os espécimes foram coletados através de mergulho livre ou autônomo. Foram utilizados martelo, ponteira e saco de tela de nylon para guardar o material durante a coleta. Para a determinação da cobertura das algas foi utilizado um transecto de linha (Figueiredo \& Steneck, 2002) dispostos horizontalmente para cada habitat, tendo $10 \mathrm{~m}$ de comprimento, onde apenas 1 amostra foi retirada de cada um dos 30 pontos aleatórios. Os habitats estudados foram a faixa de dominância de Sargassum (3-5 m de profundidade), Codium (1-3 m de profundidade) e na franja do mesolitoral no lado esquerdo da praia; e na faixa dominada por algas calcárias incrustantes (2-4 $\mathrm{m}$ de profundidade) caracterizadas por uma alta densidade de ouriços no lado direito da praia. $\mathrm{O}$ material coletado foi colocado em recipientes (caixa térmica) contendo água do mar para ser transportado até o laboratório, aonde foi armazenado em aquários sob condições controladas $\left(22-24^{\circ} \mathrm{C}\right.$ de temperatura e $68 \mathrm{mmol} \mathrm{m}^{-2} \mathrm{~s}^{-1}$ de intensidade luminosa). Com ajuda de um microscópio estereoscópico (32 a 500 x) foram observadas as características superficiais do talo, como: cor, textura, forma de conceptáculo e tipo de margem, aqueles exemplares com maior semelhança foram separados por grupos taxonômicos. Após a triagem dos grupos, estes foram colocados em frascos com solução de formol (4\%), devidamente numerados com etiquetas para posterior análise. Os dados foram convertidos para porcentagem de cobertura. A variação no tempo foi analisada para os habitats, exceto para a zona dominada pelos ouriços visto que aparentemente não houve mudança na cobertura nas épocas estudadas.

\section{Descrição das algas calcárias}

Na identificação taxonômica foram analisadas somente as algas coralíneas epilíticas. $\mathrm{Na}$ diferenciação inicial dos grupos morfofuncionais foram utilizadas as características externas de cada grupo morfológico (Steneck 1986). Quando possível foram realizados cortes histológicos (método em Moura et al. 1997) e análise em microscópios óticos e eletrônico de varredura para as medidas das estruturas. Os trabalhos utilizados para a identificação dos gêneros de algas calcárias incrustantes foram Adey \& Adey (1973), Irvine \& Chamberlain (1994), Woelkerling (1988) e Horta (2002) e para as outras macroalgas consultou-se algumas floras regionais (exemplos: Joly 1965, Yoneshigue 1985). As características observadas nas algas coralíneas foram:

Características vegetativas (morfologia externa):

- superfície do talo (topografia plana, protuberante ou ramificada e microtopografia lisa ou rugosa).

- margem (aderente e formas inteiras, lobada ou com orbitas na superfície). - confluência entre talos de indivíduos (lisa, crespa ou recobrindo outro talo).

- espessura e coloração do talo na alga viva.

Características vegetativas (morfologia interna):

- conexões citoplasmáticas secundárias (tipos "pit" ou fusão).

- células epiteliais (forma e número de camadas). 
- organização do talo (dímero ou monômero).

- tricocistos (presença e localização).

Características reprodutivas:

- conceptáculos tetra / bispóricos (uni ou multiporado).

- posição do conceptáculo no talo (elevados, nivelados ou afundados na superfície).

- forma do conceptáculo (dimensões das cavidades, presença de anéis e columela).

Foram anotadas no campo observações sobre os seguintes fatores: direção da exposição às ondas, profundidade e herbivoria.

\section{Resultados \\ Descrição taxonômica}

$\mathrm{Na}$ descrição dos grupos das algas calcárias incluíram-se somente as espécies mais comuns.

Hydrolithon samoënse (Foslie) D. Keats \& Y. Chamberlain - Talo de coloração rósea parda a marrom-claro, com superfície lisa e plana. Organização celular monômera dorsiventral, com porções dímeras, células do epitalo arredondadas, formando uma única camada e células do peritalo conectadas por fusão (Fig. 2a) medindo de 7,97 a $10,69 \mu \mathrm{m}$ de altura e 2,5 a 5,9 $\mu \mathrm{m}$ de largura. Tricocistos presentes isolados e dispersos no talo. Conceptáculo plano, uniporado (Fig. 2b) com distinta auréola branca ao seu redor, diâmetro externo de 100$225 \mu \mathrm{m}$ e cavidade interna elíptica com 92 a $125 \mu \mathrm{m}$ de largura e 65 a $70 \mu \mathrm{m}$ de altura, apresentando duas ou três camadas de células na parede superior e células dispostas verticalmente ao redor do poro. Tetrasporângios zonados medindo de 7,97 a 10,69 $\mu \mathrm{m}$ de altura e 2,5 a 5,9 $\mu \mathrm{m}$ de largura, sem fila-mentos calcificados entre esporângios. Planta abundante coletada no mesolitoral eno sublitoral (barren rocks), local dominado por algas calcárias e ouriços e com maior frequiência de ondas, e também encontrada nas zonas de $C$. spongiosum e $S$. furcatum, podendo estar sombreada por esta última macroalga.
Spongites sp. - Talo de coloração marrom com superfície lisa à irregular, apresentando desprendimento das células epiteliais, margem branqueada e pouco aderida, com até $250 \mathrm{~mm}$ de espessura. Organização celular monômera dorsiventral. Células epiteliais arredondadas em única camada, entremeadas por tricocistos e células periteliais conectadas por fusão. Conceptáculo uniporado, elevado triangular (Figura 2c), com diâmetro externo de 500-600 $\mu \mathrm{m}$ e interno de 450-600 $\mu \mathrm{m}$ com células dispostas horizontalmente ao redor do poro. Tetrasporângios zonados. Planta abundante coletada no mesolitoral encontrada nas bordas das fendas da rocha descobertas de epífitas, e no sublitoral na zona de C. spongiosum.

Lithophyllum sp. - Talo de coloração rósea, vinácea clara a escuro com superfície lustrosa protuberante com desprendimento das células do epitalo. Organização celular monômera dorsiventral a dímera. Células do epitalo arredondadas em única camada e células subepiteliais quadráticas. Células do peritalo mais altas do que largas unidas lateralmente por conexões citoplasmáticas (Fig. 2d). Conceptáculos esporofíticos uniporados planos a pouco elevados, arredondado com poro proeminente, diâmetro externo de $125-400 \mu \mathrm{m}$ e cavidade interna medindo de $78-300 \mu \mathrm{m}$ de largura por 35-90 $\mu \mathrm{m}$ de altura, com columela interna e quatro a cinco camadas de células na parede superior. Conceptáculos afundados no talo quando senescentes (Fig. 2e). Tetrasporângios zonados sem filamentos calcificados entre os esporângios medindo 31,8 $\mu \mathrm{m}$ de altura e $23,4 \mu \mathrm{m}$ de largura. Três morfótipos foram inicialmente distinguidos nos transectos (codificados como sp 1, sp 2, sp 3), segundo os tamanhos e formas de conceptáculos. Contudo, as sobreposições das dimensões dos conceptáculos levam a crer serem um único táxon. Planta abundante coletada no sublitoral na zona de $C$. spongiosum e na zona de $S$. furcatum e no mesolitoral. 

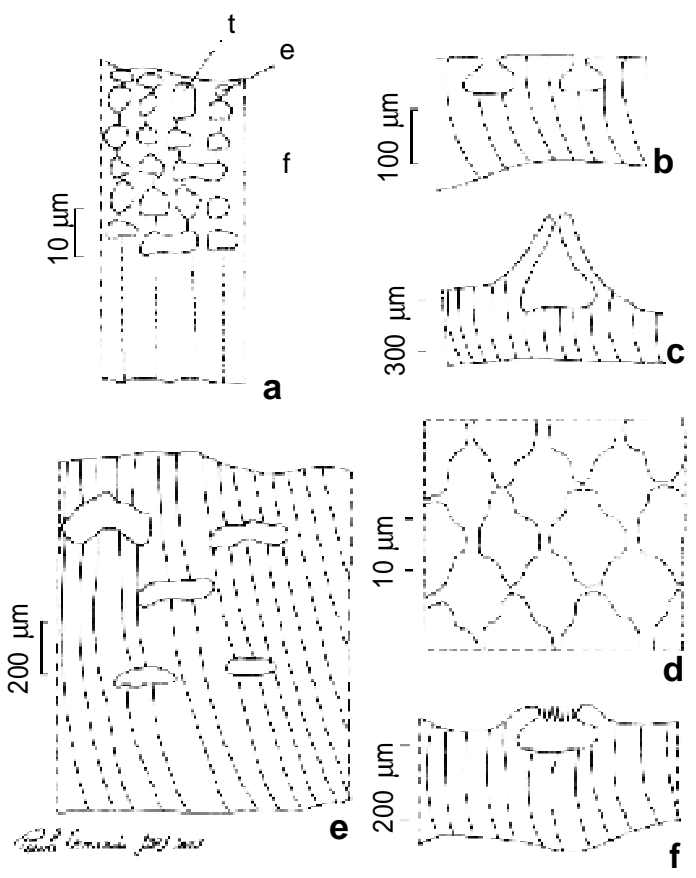

Figura 2 - Diagrama ilustrativo das características principais utilizadas para identificação dos táxons de algas calcárias incrustantes encontradas. a - detalhe do talo de H. samoënse com células epiteliais arredondadas (e), tricocisto (t) e células do peritalo conectadas por fusão (f); b - conceptáculo plano uniporado de H. samoënse; c - conceptáculo uniporado, elevado triangular de Spongites sp.; d - células do peritalo de Lithophyllum sp. conectadas por conexões celulares secundárias; e - conceptáculo afundado no talo de Lithophyllum sp. quando senescente; f - conceptáculo multiporado de Melobesioideae.

Alga indeterminada da subfamilia Mastophoroideae (sp. 1) - Talo de coloração violeta claro com superfície lisa. Organização celular monômera dorsiventral, células epiteliais arredondadas, células do peritalo conectadas por fusão. Conceptáculo plano, uniporado, com diâmetro externo de 75-100 $\mu \mathrm{m}$, sem esporângios no seu interior. Planta rara coletada no sublitoral barren rocks.

Alga indeterminada da subfamilia Mastophoroideae (sp. 2) - Talo de coloração rosa-claro com superfície pouco protuberante. Organização celular monômera, células epiteliais arredondadas em uma ou duas camadas e células periteliais conectadas por fusão. Conceptáculo uniporado, elevado, arredondado, com auréola branca ao redor, diâmetro externo de $300 \mu \mathrm{m}$ e interno de $300-$ $350 \mu \mathrm{m}$. Planta carposporofítica coletada raramente no sublitoral na zona de $S$. furcatum.

Alga indeterminada da subfamilia Melobesioideae - Talo de coloração violácea com superfície pouco protuberante, apresentando, conceptáculo multiporado elevado arredondado (Fig. 2f) com diâmetro externo de $150 \mu \mathrm{m}$. Planta rara coletada no sublitoral zona de $C$. spongiosum.

Alga vegetativa - indeterminada visto o talo ser vegetativo, coletadas nas zonas de $S$. furcatum, C. spongiosum e em área com alta densidade de ouriços herbívoros.

\section{Distribuição dos táxons}

No sublitoral, em transecto realizado no lado esquerdo da Praia do Forno, em agosto, maio e novembro, na profundidade de $3 \mathrm{~m}$, em local dominado por $S$. furcatum, foi sempre encontrado Lithophyllum sp. como a alga calcária incrustante mais freqüente (Fig. 3).

No sublitoral, em transecto realizado no lado esquerdo da Praia do Forno, em agosto e maio, na profundidade de 2,2-2,5 m, em local dominado por C. spongiosum, foi encontrado Lithophyllum sp. como o táxon o mais freqüente de alga calcária incrustante (Fig. 4). Em novembro, houve uma substituição de Lithophyllum sp. por H. samoënse como organismo dominante (Fig. 4). Spongites sp. e a espécie indeterminada de Melobesioideae ocorrem em menor freqüência que os demais táxons.

Na zona do mesolitoral, no lado esquerdo da Praia do Forno, em local dominado por turfos de macroalgas, foram encontrados dois táxons de algas calcárias incrustantes mais freqüentes: Spongites sp. e H. samoënse. Em maio, foram encontrados quatro táxons, sendo Lithophyllum sp. mais freqüente que $H$. samoënse (Fig. 5). Em novembro, inverteuse o padrão, pois Lithophyllum sp. foi menos freqüente que $H$. samoënse. Nas duas épocas 


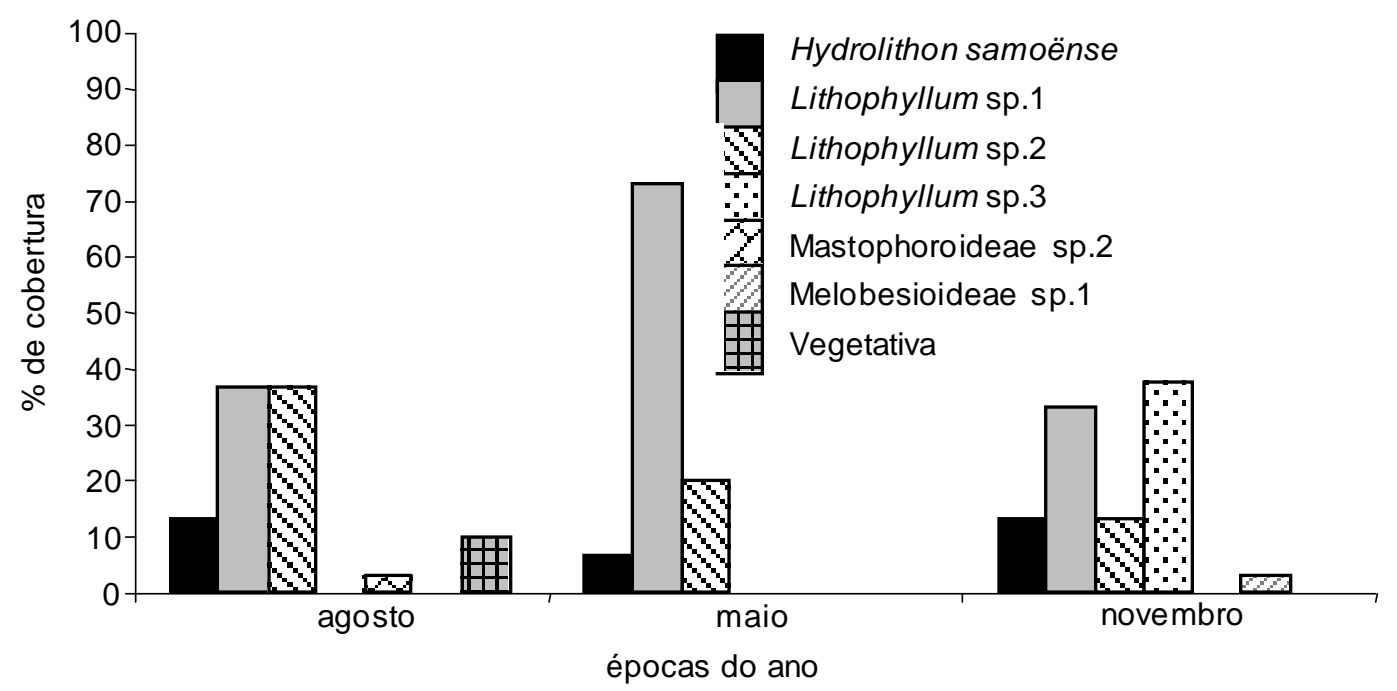

Figura 3 - Distribuição das algas calcárias na zona de S. furcatum $(\mathrm{n}=30)$.

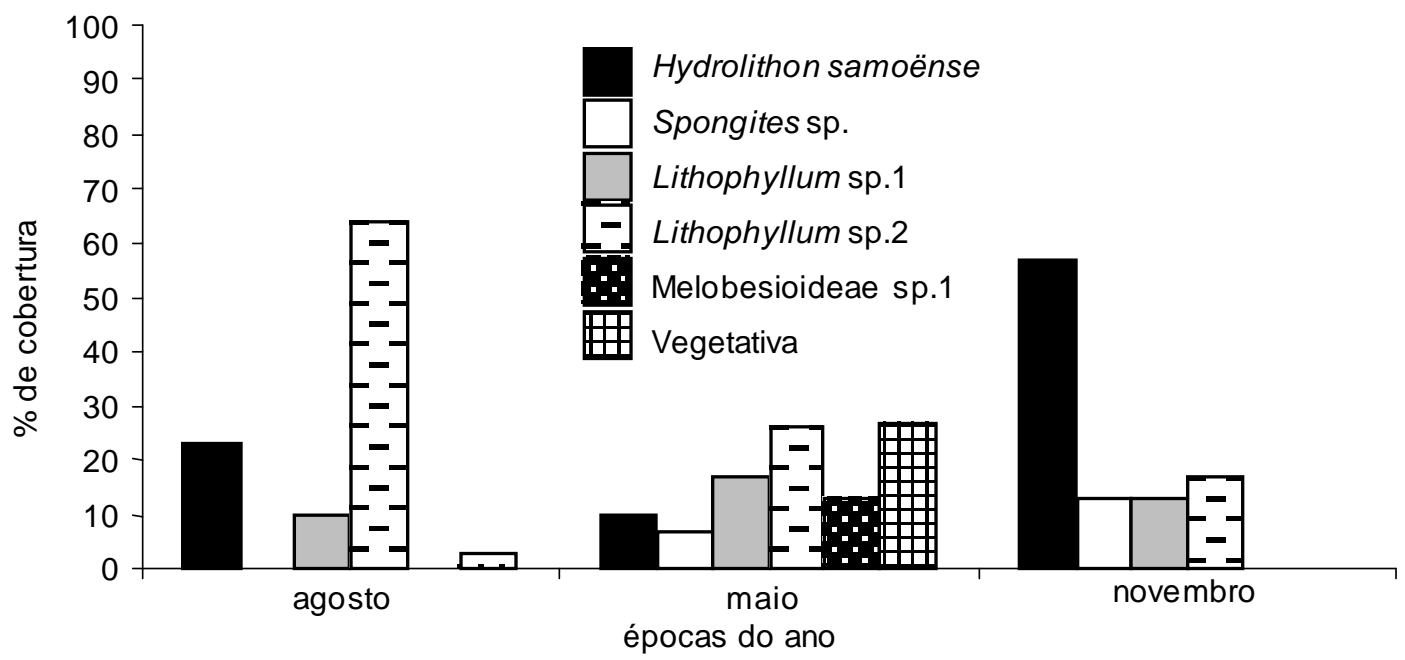

Figura 4 - Distribuição das algas calcárias na zona de $C$. $\operatorname{spongiosum~}(\mathrm{n}=30)$.

do ano Spongites sp. manteve uma cobertura relativ amente alta (Fig. 5).

No único transecto realizado no lado direito da Praia do Forno em julho, na profundidade de 2-2,5 m, em local dominado por algas calcárias e por ouriços (denominado de barren rocks), foram encontrados três táxons de algas calcárias incrustantes, sendo o mais freqüente $H$. samoënse (Fig. 6).

Os turfos de macroalgas foram compostos principalmente por Cladophora sp, Colpomenia sinuosa (Roth) Derbès \& Solier, Amphiroa beauvoisii Lamouroux, Ceramium sp, Hypnea spinella (Agardh) Kützing, Jania adhaerens Lamouroux. Ainda foram encontradas, em menor freqüência, as macroalgas Codium intertextum Collins \& Hervey, Codium spongiosum Harvey, Ulva fasciata Delile, Sargassum furcatum Kützing e Laurencia obtusa (Hudson) Lamouroux. 


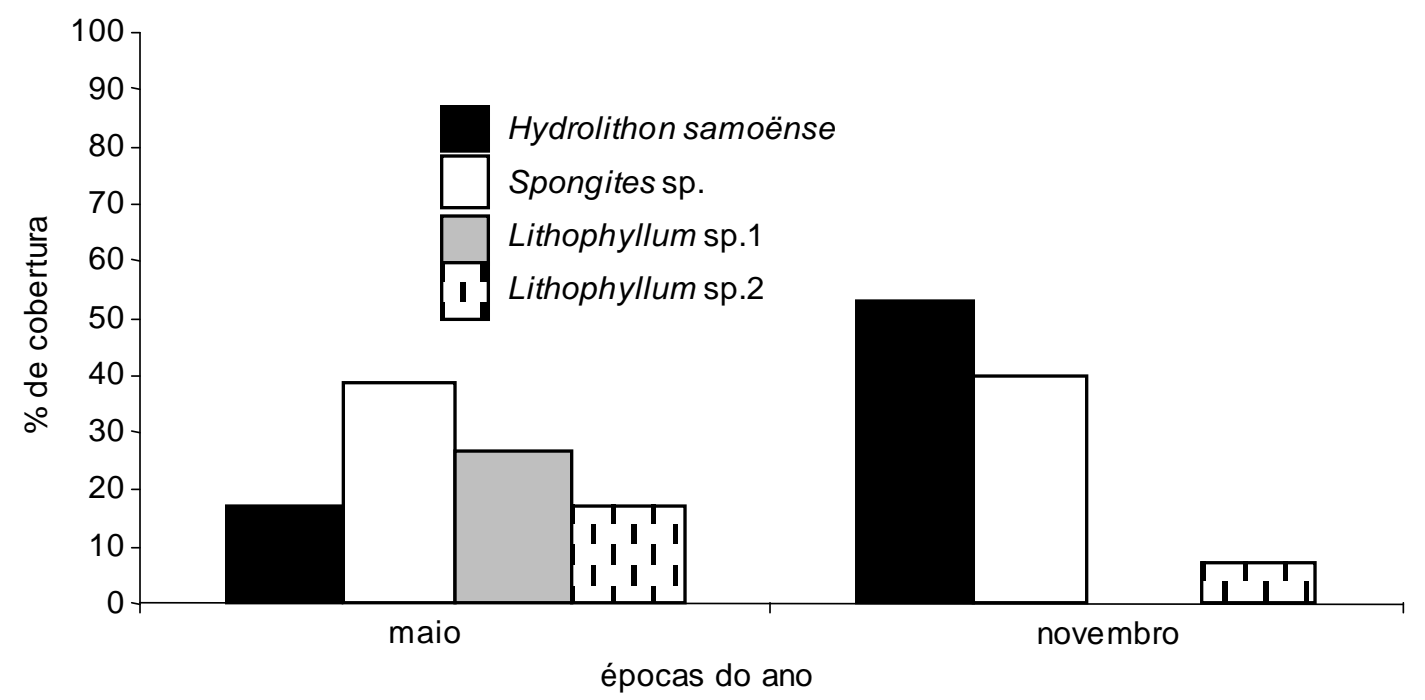

Figura 5 - Distribuição das algas calcárias na zona do mesolitoral $(n=30)$.

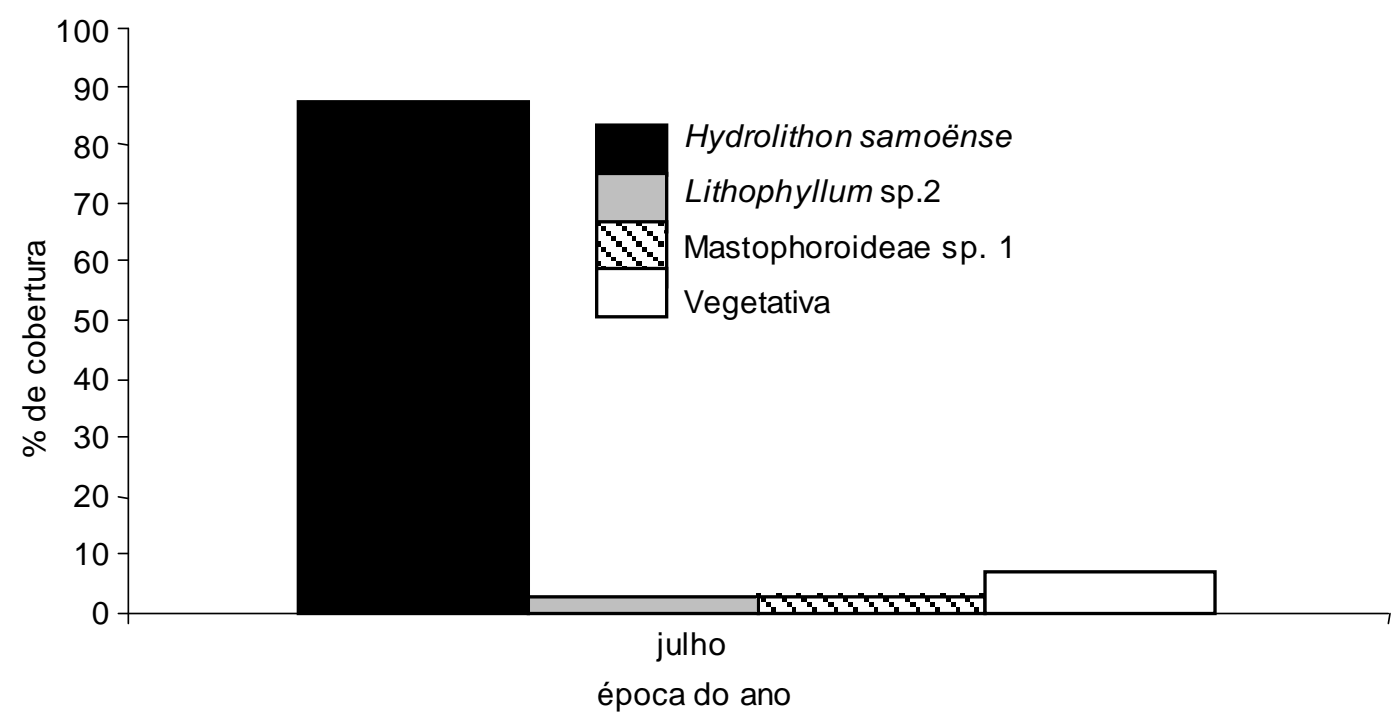

Figura 6 - Distribuição das algas calcárias em local com alta densidade de ouriços herbívoros $(\mathrm{n}=30)$.

\section{Discussão}

A plasticidade morfológica nas algas calcárias deve explicar a semelhança entre indivíduos de $H$. samoënse com outras espécies não identificadas de Mastophoroideae. Esta única espécie identificada possui coloração distinta e conceptáculos circundados por uma auréola branca. As outras duas espécies indeterminadas desta subfamília apresentaram conceptáculos planos e de tamanhos próximos, contudo a ausência de esporângios nos conceptáculos tornou impossível a confirmação do táxon. A forma triangular e o maior conceptáculo de Spongites sp. a distinguiu das demais espécies de Mastophoroideae.

Lithophyllum sp. que tem conceptáculos uniporados planos foi identificado no campo principalmente pelo talo lustroso e protuberante, forma plana do conceptáculo com poro ligeiramente elevado e ausência de auréola branca ao seu redor. Em contraste, as algas 
Melobesioideae se diferenciaram pelos conceptáculos esporofíticos multiporados (Woelkerling 1988).

A alga calcária identificada como pertencente a espécie $H$. samoënse (Mastophoroideae - Corallinaceae) tem características marcantes. Neste gênero segundo Irvine \& Chamberlain (1994) o talo é monômero com partes dímeras, células conectadas por fusão e o conceptáculo tetraspórico uniporado coberto por duas ou mais camadas de células e uma outra epitelial no topo. A espécie estudada diferencia-se das demais no gênero pela característica presença de três camadas de células na parede superior do conceptáculo (Keats \& Chamberlain 1994). Estas algas são distinguidas do gênero próximo Spongites, da mesma subfamília, pela disposição vertical das células ao redor do poro do conceptáculo enquanto Spongites tem células dispostas horizontalmente (Penrose \& Woelkerling 1992). Ambos táxons ocorrem principalmente no mesolitoral cobertos ou não por algas em turfos.

As algas calcárias foram identificadas como pertencentes ao gênero Lithophyllum (Lithophylloideae - Corallinaceae) por possuirem talo dorsiventral dímero a monômero, células com conexões citoplasmáticas secundárias, ausência de hipotalo em paliçada e conceptáculo tetraspórico uniporado (Irvine \& Chamberlain 1994). Contudo a au-sência de conceptáculos gametofíticos impossibilitou a identificação da espécie (Woelkerling \& Campbell 1992). Este táxon ocorre no sublitoral coberto pelas macroalgas, $C$. spongiosum e S. furcatum.

Como características ecológicas, $H$. samoënse apresenta conceptáculos planos assim como o esperado para as algas calcárias dominantes em locais suscetíveis à uma elevada ação de ouriços herbívoros, o que provavelmente favorece a sua sobrevivência. Entretanto, plantas com conceptáculos planos também coexistiram com as algas calcárias de conceptáculo elevado no mesolitoral, aonde a pressão de herbivoria é moderada. Spongites sp. possui conceptáculo elevado e provavelmente vive refugiada dos herbívoros na borda de fendas na região entre marés, estando também protegida contra a dessecação. Lithophyllum sp., com conceptáculo elevado, vive no sublitoral exposto a maior sedimentação sob baixa pressão de herbivoria e coberta por macroalgas sob baixa intensidade luminosa. Espécies distintas dentro de um mesmo gênero de algas calcárias incrustantes, estão adaptadas a diferentes níveis de intensidade luminosa (Leukart 1994). A topografia da superfície do talo destas algas também pode indicar o tipo de habitat, onde superfícies mais planas de $H$. samoënse e Spongites sp. ocorrem em locais com alta herbivoria e talos mais rugosos e protuberantes de Lithophyllum sp. ocorrem em locais com baixa herbivoria por equinóides - ouriços (Steneck 1986).

Em resumo, foram coletados cinco táxons diferentes de algas calcárias incrustantes, como os mais abundantes. Houve uma discreta variação temporal na distribuição dos gêneros dominantes, Lithophyllum e Hydrolithon, exceto Spongites que manteve sua abundância relativamente estável. Hydrolithon e Spongites ocorreram em áreas rasase foram expostas a freqüentes distúrbios físicos. Em áreas rasas e expostas às ondas no litoral de Búzios existe uma maior abundância de algas formadoras de turfos (Oigman-Pszczol et al. 2004), porém as atividades antiincrustantes destas algas calcárias deve favorecê-las, limitando o desenvolvimento de algas epífitas de pequeno porte, como Enteromorpha, Ulva e Hincksia (Villas-Bôas \& Figueiredo 2004). Por outro lado, Lithophyllum foi mais abundante em áreas protegidas da ação dos distúrbios físicos. Contudo, a densa cobertura de Sargassum deve limitar o desenvolvimento de algas epífitas na sua superfície, assim como o observado para algas calcárias cobertas por algas formadoras de dossel (Figueiredo et al. 1997). A distribuição dos grupos morfo-funcionais/ taxonômicos de algas calcárias incrustantes 
parece ser fortemente influenciada pelos diferentes habitats e concordou, de um modo geral, com padrões descritos por Steneck (1986) e Steneck \& Dethier (1994) em função dos distúrbios bióticos e abióticos.

\section{Agradecimentos}

Agradecemos a Derek W. Keats pela confirmação da identificação de $H$. samoënse, Gavin W. Maneveldt e Carmen Ras pelo apoio na microscopia eletrônica e a Paulo Ormindo pelas ilustrações dos diagramas. Ao Conselho Nacional de Desenvolvimento Científico e Tecnológico - CNPq (processo $\mathrm{n}^{\circ}$ 523245/96-3) e à Fundação de Amparo à Pesquisa do Estado do Rio de Janeiro FAPERJ (processo $n^{\circ}$ E-26/150.807/1999), que concederam bolsas para o primeiro autor.

\section{REFERÊNCIAS BibLIOGRÁFICAS}

Adey, W. H. 1966. Distribution of saxicolous crustose corallines in the northwestern North Atlantic. Journal of Phycology 2: 49-54.

1971. The sublittoral distribution of crustose corallines on the Norwegian coast. Sarsia 46: 41-58.

Adey, W. H. \& Adey, P. J. 1973. Studies on the biosystematics and ecology of the epilithic crustose corallinaceae of the British Isles. British Phycological Journal 8: 343-407.

Adey, W. H. \& Vassar, J. M. 1975. Colonization, succession and growth rates of tropical crustose coralline algae (Rhodophyta, Cryptonemiales). Phycologia 14: 55-69.

Figueiredo, M. A. de. O. 1997. Colonization and growth of crustose coralline algae in Abrolhos, Brazil. Proceedings of the $8^{\text {th }}$ International Coral Reef Symposium 1: 689-694.

Figueiredo, M. A. de. O., Norton, T. A. \& Kain (Jones), J. M. 1997. Settlement and survival of epiphytes on two intertidal crustose coralline algae. Journal of
Experimental Marine Biology and Ecology 213: $247-260$.

Figueiredo, M. A. de. O. \& Steneck R. S. 2002. Floristic and ecological studies of crustose coralline algae on Brazil's Abrolhos reefs. Proceedings of the $9^{\text {th }}$ International Coral Reef Symposium 1: 493-498.

Horta, P. A. 2002. Bases para a identificação das corallinaceas não articuladas do litoral brasileiro - uma síntese do conhecimento. Biotemas 15(1): 7-44.

Irvine, L. M. \& Chamberlain, Y. M. 1994. Seaweeds of the British Isles. London: The Natural Hystory Museum.

Joly, A. B. 1965. Flora Marinha do litoral Norte do estado de São Paulo e regiões circunvizinhas. Boletim Faculdade Filosofia da Universidade de São Paulo 294: 1-239.

Keats, D. W. \& Chamberlain, Y. M. 1994. Three species of Hydrolithon (Rhodophyta, Corallinaceae): Hydrolithon onkodes (Heydrich) Penrose and Woelkerling, Hydrolithon superficiale sp. nov., and Hydrolithon samoënse (Foslie) comb. Nov. from South Africa. South Africa Journal of Botany 60(1): 8-21.

Leukart, P. 1994. Field and laboratory studies on depth dependence, seasonality and light requirement of growth in three species of crustose coralline algae (Rhodophyta, Corallinales). Phycologia 33: 281-290.

Littler, M. M. 1972. The crustose Corallinaceae. Oceanography and Marine Biology Annual Review 10: 311-347.

Littler, M. M. \& Littler, D. S. 1980. The evolution of thallus form and survival strategies in benthic marine macroalgae: field and laboratory tests of a functional form model. The American Naturalist 116: 25-44.

Littler, M. M. \& Littler, D. S. 1984. Relationships between macroalgal functional form groups and substrata stability in a subtropical rocky intertidal 
system. Journal of Experimental Marine Biology and Ecology 74: 13-34.

Moura, C. W. do N.; Kraus, J. E. \& CordeiroMarino, M. 1997. Metodologia para obtenção de cortes histológicos com historresina e coloração com azul de toluidina $\mathrm{O}$ para algas coralináceas (Rhodophyta, Coralinales). Hoehnea 24(2): 17-27.

Naim, O. 1993. Seasonal responses of a fringing reef community to eutrophication (Réunion Island, Western Indian Ocean). Marine Ecology Progress Series 99: 137-151.

Oigman-Pszczol, S. S.; Figueiredo, M. A. de O. \& Creed, J. C. 2004. Distribution of benthic communities on the trpical rocky subtidal of Armação dos Búzios, Southeastern Brazil. Marine Ecology 25 (3): 173-190.

Penrose, D. \& Woelkerling, W. J. 1992. A reappraisal of $\mathrm{Hydrolithon}$ and its relationship to Spongites (Corallinacea, Rhodophyta). Phycologia 31: 81-88.

Steneck, R. S. 1986. The ecology of coralline algal crusts: convergent patterns and adaptive strategies. Annual Review of Ecological Systematics 17: 273-303.

1990. Herbivory and the evolution of nongeniculate coralline algae (Rhodophyta, Corallinales) in the North Atlantic and North Pacific. In: Evolutionary Biogeography of the Marine Algae of the North Atlantic, (D. J. Garbary and G.R. South ed,) SpringerVerlag, Berlin Heidelberg p. 107-129.

Steneck, R. S. \& Paine, R. T. 1986. Ecological and taxonomic studies of shallow-water encrusting Corallinaceae (Rhodophyta) of the boreal northeastern Pacific. Phycologia 25: 221-240.

Steneck, R. S. \& Dethier, M. N. 1994. A functional group approach to the structure of algal-dominated communities. Oikos 69: 476-498.

Steneck, R. S.; Hacker, S. D. \& Dethier, M. N. 1991. Mechanisms of competitive dominance between crustose coralline algae: an herbivore-mediated competitive reversal. Ecology 72(3): 938-950.

Valentin, J. L.; Andre D. L.; Monteiro-Ribas, W. M. \& Tenenbaum, D. R. 1978. Hidrologia e plancton da região costeira entre Cabo Frio e o estuário do Rio Paraíba (Brasil). Instituto de Pesquisas da Marinha, Rio de Janeiro, 127: 24.

Villas-Bôas, A. B. \& Figueiredo, M. A. O. 2004. Are anti-fouling effects in coralline algae species specific? Brazilian Journal of Oceanography 52(1): 11-18.

Woelkerling, W. J. 1988. The coralline red algae: an analysis of the genera and subfamilies of nongeniculate Corallinaceae. British Museum Natural History and Oxford University Press, London and Oxford.

Woelkerling, W. J. \& Campbell, S. J. 1992. An account of southern Australian species of Lithophyllum (Corallinaceae, Rhodophyta). Bulletin British Museum Natural History (Botany) 22(1): 1-107.

Yoneshigue, Y. 1985. Taxonomie et ecologie des algues marines dans la region de Cabo Frio (Rio de Janeiro, Brésil). These de Docteur d'Etat-Sciences thesis, Universite d'Aix-Marseille II. 
